\title{
Struktura złączy lutospawanych metodą CMT stali ocynkowanej ogniowo
}

\section{The structure of CMT brazed hot-dip galvanized steel joints}

\section{Streszczenie}

Badano strukturę złączy doczołowych stali ocynkowanej ogniowo, otrzymanych niskoenergetyczną metodą CMT. Wykazano, że tworzą się złącza o wysokiej jakości, bez naruszenia powłoki cynku w pobliżu spoiny. Cynk tworzy roztwór z miedzią, natomiast krzem segreguje na granicy międzyfazowej ze stalą, a w miejscach, gdzie dochodzi do niewielkich nadtopień podłoża, tworzą się roztwory Fe-Si.
Abstract

The structure of hot-dip galvanized steel butt joints, obtained by the CMT low energy method was investigated. It has been shown that high quality joints are formed, without damaging the zinc coating near the weld. The zinc forms a solution of copper, and silicon segregate at the interface with the steel. In places where there is a small partial melting of the substrate the Fe-Si solutions are being formed.

\section{Wstęp}

Lutospawanie jako technologia spajania metali jest znane już od dawna, ale ostatnio rozwija się dynamicznie. Obok dobrze znanych i wielokrotnie opisywanych, także w krajowej literaturze technicznej, technologii wykorzystujących „klasyczne” metody spawania łukowego w osłonie gazów, pojawiły się informacje o zastosowaniu do tego celu laserów, diodowego i dyskowego, a także niskoenergetycznych metod: ColdArc, STT i CMT (np. $[1 \div 6]$ ).

Lutospawanie jest dobrą metodą łączenia blach ocynkowanych, z uwagi na zachowanie powłoki ochronnej w obszarze przylegającym do złącza, co nie jest możliwe przy spawaniu takich blach. Jednak i w tym przypadku należy wziąć pod uwagę to, że typowe spoiwa stosowane do tego celu na bazie miedzi mają temperaturę topnienia rzędu $1000^{\circ} \mathrm{C}$, natomiast temperatura topnienia i wrzenia czystego cynku wynosi odpowiednio $419,5^{\circ} \mathrm{C}$ i $907^{\circ} \mathrm{C}$. Z tego względu blachy $z$ cieńszymi powłokami galwanicznymi na bazie cynku stwarzają mniej problemów niż blachy cynkowane ogniowo.

Dr inż. Jerzy Jakubowski, dr inż. Mariusz Bober, Tomasz Rudaś - Politechnika Warszawska.
Lutospawanie blach ocynkowanych, w tym zwłaszcza galwanicznie, może być prowadzone różnymi metodami, o czym świadczą liczne publikowane wyniki badań, także krajowych: MIG/MAG [7, 8], TIG [3], PTA [9], laserem [10]. Szczególnie skuteczne są metody o niskiej, kontrolowanej energii liniowej [11], umożliwiające nawet lutospawanie stopami cynku o temperaturze topnienia zaledwie ok. $450^{\circ} \mathrm{C}$. W tym przypadku warstwa cynku pozostaje zupełnie nienaruszona w złączu (metoda ColdArc [6]).

W ramach niniejszej pracy badano strukturę złączy blach stalowych z grubą powłoką cynku nałożoną metodą ogniową, uzyskanych przy zastosowaniu niskoenergetycznej metody CMT.

\section{Przygotowanie próbek}

\section{Materiały do badań}

Próby lutospawania wykonano na ocynkowanych ogniowo blachach ze stali niskowęglowej GALV DX52D+Z275-M-A-CE wg EN 10346. Skład chemiczny tej stali oraz jej właściwości mechaniczne przedstawiono w tablicach I i II. Na rysunku 1a przedstawiono ciągła powłokę cynku o grubości $19 \div 21 \mu \mathrm{m}$ na powierzchni blachy, a na rysunku $1 \mathrm{~b}$ mikrostrukture stali. Widoczne sa wyraźnie ukierunkowane na skutek przeróbki plastycznej ziarna ferrytu. 
Tablica I. Skład chemiczny stali GALV - DX52D+Z275-M-A-CE wg atestu producenta i równowaćnik węgla C , \% wag., reszta Fe Table I. Chemical composition of GALV - DX52D+Z275-M-A-CE steel acc.g to certificate of the manufacturer, \% mas., Fe balance

\begin{tabular}{|c|c|c|c|c|c|c|c|c|c|}
\hline $\mathrm{C}$ & $\mathrm{Mn}$ & $\mathrm{P}$ & $\mathrm{S}$ & $\mathrm{Si}$ & $\mathrm{Al}$ & $\mathrm{Nb}$ & $\mathrm{Cu}$ & $\mathrm{Ni}$ & $\mathrm{C}_{\mathrm{e}}$ \\
\hline 0,028 & 0,181 & 0,006 & 0,005 & 0,014 & 0,034 & 0,001 & 0,021 & 0,019 & 0,0605 \\
\hline
\end{tabular}

Tablica II. Właściwości mechaniczne GALV - DX52D+Z275-M-A-CE Table II. Mechanical properties of GALV - DX52D+Z275-M-A-CE

\begin{tabular}{|c|c|c|c|}
\hline Próbka & $R_{e}, M P a$ & $R_{m}, M P a$ & $A_{\text {min }}, \%$ \\
\hline 2719 & 259 & 334 & 33 \\
\hline 2745 & 263 & 342 & 33 \\
\hline
\end{tabular}

Materiał dodatkowy do spawania stanowił drut lity CuSi3Mn o średnicy 1,0 mm wyprodukowany przez firmę Bedra. Skład chemiczny i właściwości mechaniczne tego drutu wg EN 10204 zamieszczono w tablicach III i IV. Temperatura topnienia spoiwa CuSi3Mn nie przekraczała $1050^{\circ} \mathrm{C}$.

\section{Wykonanie złączy}

Próby lutospawania wykonano na stanowisku zrobotyzowanym wyposażonym w robota przemysłowego IRp6. Przed procesem blachy dokładnie oczyszczono wodnym roztworem kwasu solnego. Wykonano serię
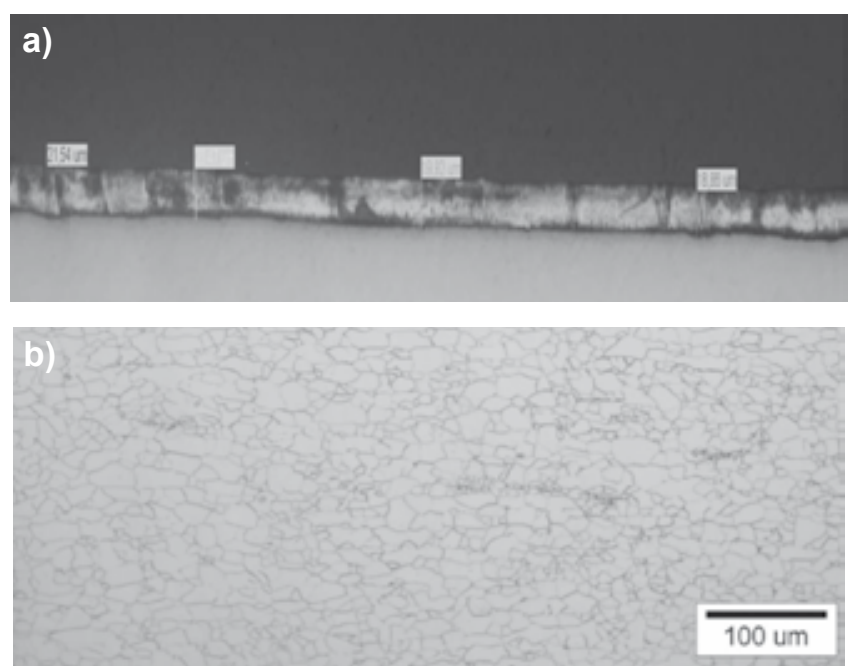

Rys. 1. Struktura materiału rodzimego: a) widok naniesionej powłoki cynku, b) mikrostruktura blachy stalowej

Fig. 1. The structure of base material: a) the view of deposited zinc coating, b) the microstructure of steel shee

Tablica III. Skład chemiczny drutu litego CuSi3Mn wg EN 10204, \% wag.

Table III. Chemical composition of CuSi3Mn solid wire acc. to EN 10204, wt.\%.

\begin{tabular}{|c|c|c|c|c|c|c|c|c|c|c|}
\hline $\mathrm{Cu}$ & $\mathrm{Ag}$ & $\mathrm{Al}$ & $\mathrm{Mn}$ & $\mathrm{Fe}$ & $\mathrm{Ni}$ & $\mathrm{P}$ & $\mathrm{Pb}$ & $\mathrm{Si}$ & $\mathrm{Sn}$ & $\mathrm{Zn}$ \\
\hline reszta & do 0,05 & do 0,01 & $\begin{array}{c}0,75 \\
-0,95\end{array}$ & do 0,10 & do 0,05 & do 0,02 & do 0,01 & $\begin{array}{c}2,80 \\
-2,95\end{array}$ & do 0,05 & do 0,10 \\
\hline
\end{tabular}

Tablica IV. Właściwości mechaniczne drutu litego CuSi3Mn wg EN 10204 Table IV. Mechanical properties of CuSi3Mn solid wire acc. to EN 10204

\begin{tabular}{|c|c|c|}
\hline $\begin{array}{c}\text { Średnica drutu } \\
\mathrm{mm}\end{array}$ & $\mathrm{R}_{\mathrm{m}}, \mathrm{MPa}$ & $\mathrm{A}_{5}, \%$ \\
\hline $0,97-0,99$ & $900-1100$ & $1-5$ \\
\hline
\end{tabular}

badań wstępnych dla różnych wariantów parametrów zmiennych, takich jak: I - natężenie prądu, U - napięcie łuku, $\mathrm{V}_{\mathrm{sp}}$ - prędkość lutospawania, $\mathrm{V}_{\mathrm{e}}$ - prędkość podawania drutu elektrodowego, $\mathrm{L}_{\mathrm{w}}-$ długość wolnego wylotu elektrody, $\Delta \mathrm{L}-$ korekta długości łuku, $\Delta \mu-$ korekta indukcyjności, Q - wydatek gazu, S - szerokość szczeliny. Badania wstępne wykazały, że istotnymi parametrami decydującymi o poprawności wykonania złącza są m.in.: szerokość szczeliny, rodzaj gazu osłonowego oraz długość wolnego wylotu elektrody. Spawanie w osłonie czystego argonu nie przyniosło oczekiwanych efektów. Dodatek $\mathrm{CO}_{2}$ do argonu wpływał na zmniejszenie napięcia powierzchniowego stopiwa, a więc sprzyjał lepszemu kształtowaniu się spoiny. $\mathrm{Na}$ podstawie badań wstępnych ustalono parametry procesu, dla których otrzymywano poprawne spoiny (tabl. V).

\section{Badania struktury złączy}

\section{Badania makroskopowe}

Obserwacjom makroskopowym poddano wszystkie złącza lutospawane. Badania prowadzono wizualnie oraz z wykorzystaniem mikroskopu stereoskopowego.

Tablica V. Parametry procesu lutospawania Table V. The parameters of CMT brazing

\begin{tabular}{|c|c|c|c|c|c|c|c|c|c|c|}
\hline A & $\begin{array}{l}\mathrm{U} \\
\mathrm{V}\end{array}$ & $\begin{array}{c}\mathrm{V}_{\mathrm{sp}} \\
\mathrm{mm} / \mathrm{s}\end{array}$ & $\frac{\mathrm{V}_{\mathrm{e}}}{\mathrm{m} / \mathrm{min}}$ & $\underset{\mathrm{mm}}{\mathrm{L}_{\mathrm{w}}}$ & $\Delta \mathrm{L}$ & $\Delta \mu$ & $\begin{array}{c}\mathrm{Q} \\
\mathrm{dm}^{3} / \mathrm{min}\end{array}$ & $\begin{array}{c}\text { Pozycja } \\
\text { spawania }\end{array}$ & $\underset{\mathrm{mm}}{\mathrm{S}}$ & $\begin{array}{c}\text { Gaz } \\
\text { osłonowy }\end{array}$ \\
\hline 45 & 10,8 & 5 & 2,6 & $10 \div 12$ & 10 & -2 & 12 & PA & 1 & $\begin{array}{c}\mathrm{Ar}+18 \% \\
\mathrm{CO}_{2}\end{array}$ \\
\hline
\end{tabular}


Na rysunku 2 przedstawiono widok przykładowej lutospoiny od strony lica i grani. Od strony lica wyraźnie widoczna jest strefa, w której powłoka cynku uległa nadtopieniu, a następnie ponownie krystalizowała. Zarówno lico, jak i grań lutospoiny zostały prawidłowo uformowane. Od strony grani powłoka cynku jest ciągła i przylega do spoiny.

Wybrane złącza lutospawane poddano statycznej próbie rozciągania. Przeprowadzone próby wykazały, że właściwości mechaniczne złączy są wyższe niż materiału podstawowego. We wszystkich przypadkach zerwanie wystąpiło w materiale podstawowym. Na rysunku 3 przedstawiono próbkę po rozciąganiu, a $w$ tablicy VI wyniki tej próby.

Na rysunku 4 pokazano makrostrukturę lutospoiny od strony lica (a) i grani (b). Widoczny jest brak ubytków warstwy ochronnej. Morfologia powierzchni powłoki cynkowej świadczy o jej roztopieniu podczas procesu i ponownej krystalizacji po przejściu źródła ciepła (rys. 4a). Lico i grań mają prawidłowe kształty. Na przekrojach poprzecznych (rys. 4c) nie zaobserwowano niezgodności spawalniczych takich jak: pęknięcia, pęcherze gazowe lub porowatość. Granica międzyfazowa lut-podłoże jest ciągła. Zauważono tylko nieznaczne lokalne nadtopienie łączonych blach (rys. 4c).

\section{Badania mikroskopowe}

Obserwacje mikroskopowe przeprowadzono na trawionych zgładach przekrojów poprzecznych. Do obserwacji i rejestracji mikrostruktury wykorzystano stanowisko wyposażone w mikroskop świetlny Olympus IX 70 z możliwością cyfrowego zapisu obrazu. Badano złącza od strony lica i grani (rys. 5). Szczegółowo obserwowano granicę międzyfazową materiał podłoża - lutowina. Zauważono nieznaczny rozrost ziaren w materiale rodzimym tuż przy linii wtopienia (rys. 5a i b). Mikrostrukturę grani przedstawiono na rysunkach 5c i 5d. Zaobserwowano łagodne przejście grani do materiału rodzimego oraz warstwę ochronną bez uszkodzeń. Ustalono, że występują dwa charakterystyczne obszary na granicy międzyfazowej podłoże-lut. Pierwszy, kiedy powłoka cynku rozpuszcza się całkowicie w ciekłym spoiwie bez nadtopienia stalowego podłoża (rys. 5b) i drugi, kiedy topi się także warstwa cynku i jednocześnie nadtapia się lokalnie materiał podłoża (rys. 5a).

Te dwa charakterystyczne obszary badano szczegółowo, stosując mikroskop skaningowy Joel 663 wyposażony w spektrometr (WDS). W reprezentatywnych obszarach wykonano analizę jakościową powierzchniowych stężeń pierwiastków: $\mathrm{Cu}, \mathrm{Zn}, \mathrm{Fe}, \mathrm{Si}$ oraz rozkład
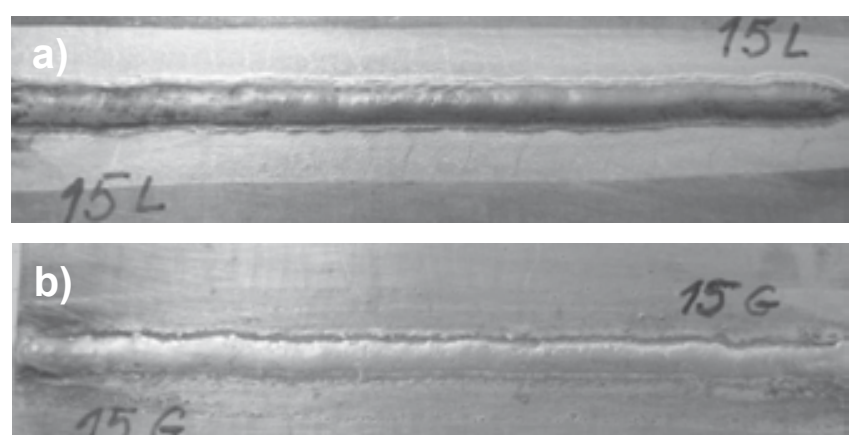

Rys. 2. Spoina od strony: a) lica, b) grani

Fig. 2. The weld from: a) the face, b) the root

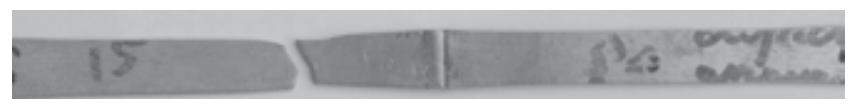

Rys. 3. Złącze po próbie rozciągania

Fig. 3. The joint after tensile testing
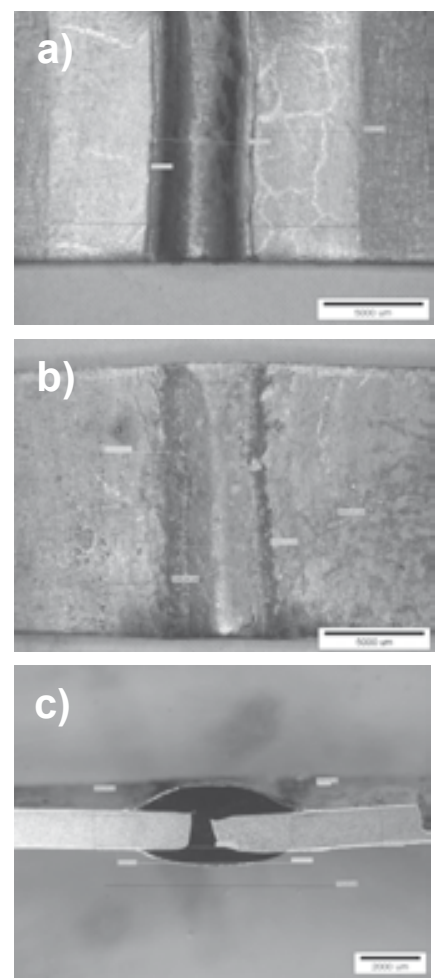

Rys. 4. Makrostruktura połączenia lutospawanego: a) widok lica, b) widok grani, c) przekrój poprzeczny

Fig. 4. The macrostructure of the CMT brazed joint: a) face view, b) root view, c) transverse cross-section

tych pierwiastków wzdłuż linii prostopadłej do granicy międzyfazowej. Na rysunku 6 przedstawiono mikrostrukturę granicy międzyfazowej z obszaru, gdzie topiła się powłoka cynku i mieszała z ciekłym lutem, a materiał podłoża nie nadtapiał się. Granica ta jest ciągła bez

Tablica VI. Wyniki statycznej próby rozciągania

Table VI. The results of static tensile testing

\begin{tabular}{|c|c|c|c|c|}
\hline Nr próbki & $\begin{array}{c}\text { Szerokość - a } \\
\mathrm{mm}\end{array}$ & $\begin{array}{c}\text { Grubość - b } \\
\mathrm{mm}\end{array}$ & $\begin{array}{c}\text { Maks. siła } \\
\text { rozciągająca, kN }\end{array}$ & $\begin{array}{c}\mathrm{R}_{\mathrm{m}} \\
\mathrm{MPa}\end{array}$ \\
\hline 15 & 14,46 & 1,21 & 6,53 & 373 \\
\hline
\end{tabular}



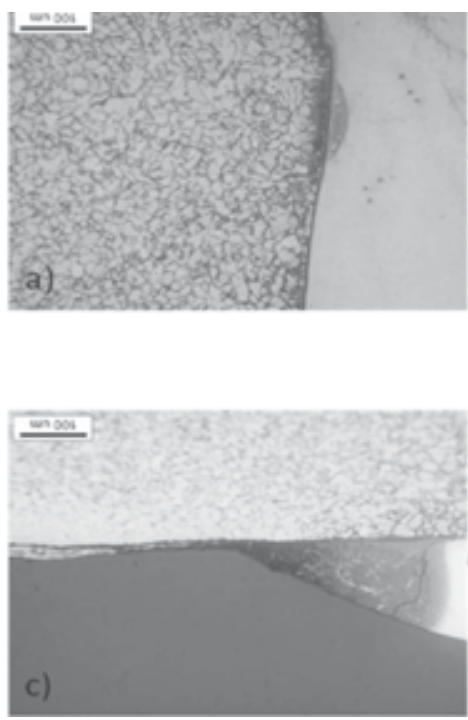
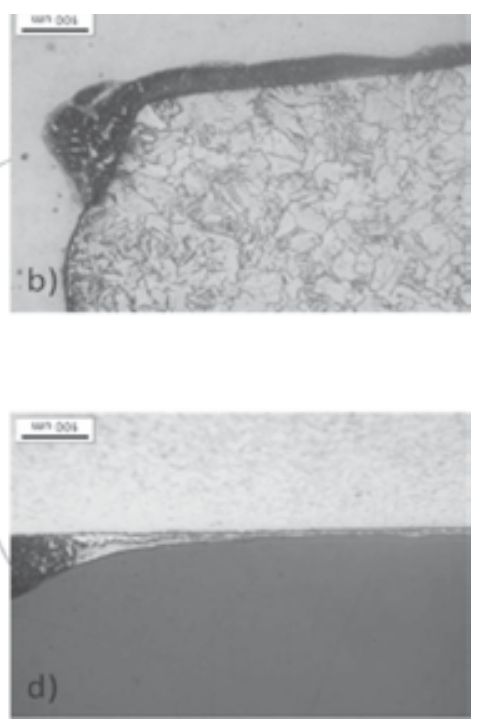

Rys. 5. Mikrostruktury lutospoiny z charakterystycznych obszarów badań od strony: a, b) lica, c, d) grani

Fig. 5. The microstructure of CMT braze with specific test areas from: $a, b)$ the face, $c, d$ ) the root

widocznej warstwy przejściowej. Na kolejnych zdjęciach pokazano rozkłady powierzchniowe stężeń analizowanych pierwiastków. Z badań tych wynika, że krzem wyraźnie segreguje w pobliżu granicy międzyfazowej, natomiast miedź i rozpuszczony cynk są równomiernie rozmieszczone w lutowinie, tworząc roztwór.
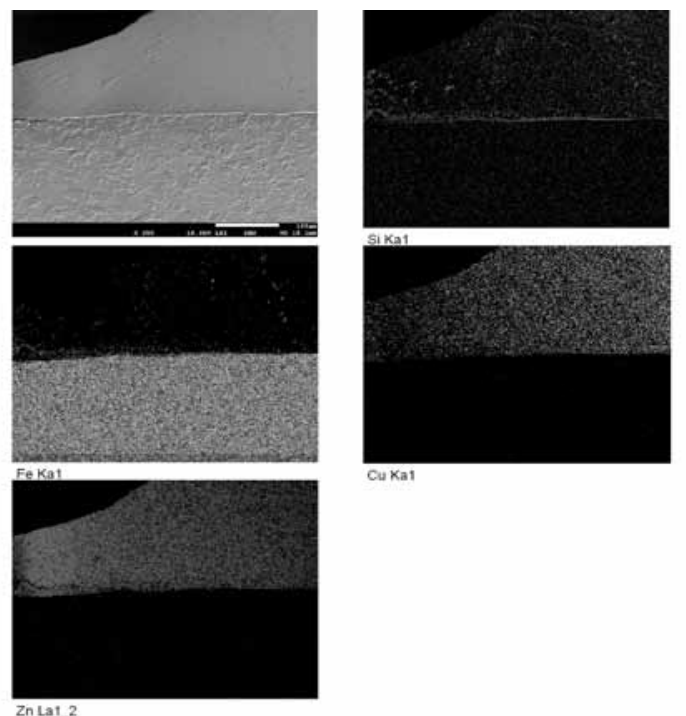

Rys. 6. Mikrostruktura granicy międzyfazowej podłoże - lut z obszaru, w którym nie nastąpiło nadtopienie blachy stalowej, oraz rozkłady powierzchniowe stężeń podstawowych pierwiastków

Fig. 6. The microstructure of substrate - braze interfacial boundary from the region where there was no melting of steel sheet and the surface distribution of concentration of the base elements

\section{Podsumowanie}

Lutospawanie z zastosowaniem niskoenergetycznej metody CMT przynosi zadowalające efekty w łączeniu blach ocynkowanych ogniowo, dając złącza o wysokiej jakości. Zredukowana wartość energii cieplnej wprowadzonej do złącza nie uszkadza warstwy cynkowej.

Badania struktury złączy wskazują na ciągłą granicę
Mikrostrukturę granicy międzyfazowej materiał rodzimy-lutowina dla przypadku, gdy dodatkowo dochodzi do lokalnego nadtopienia stalowego podłoża, przedstawiono na rysunku 7. Jakkolwiek granica ta jest ciągła, to wyraźnie widoczne są wydzielenia nowych faz. Rozkłady powierzchniowe stężeń pierwiastków wskazują, że obszar ten jest bogaty w krzem i żelazo, natomiast miedź o większym powinowactwie do cynku tworzy z nim roztwór.
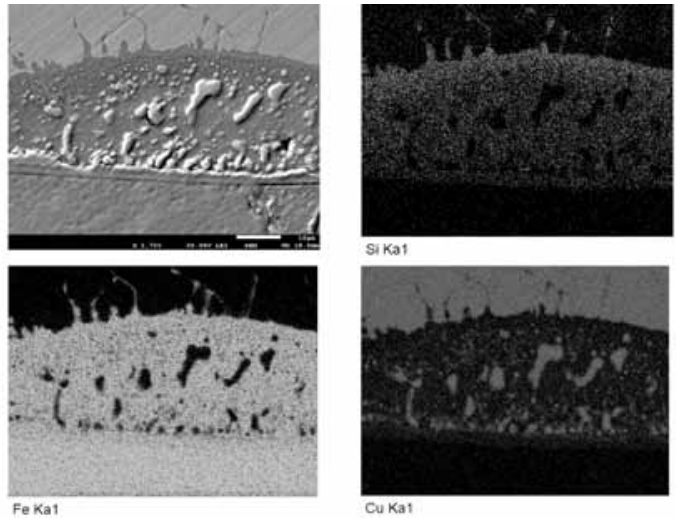

Rys. 7. Mikrostruktura granicy międzyfazowej podłoże - lut z obszaru, w którym nastąpiło lokalne nadtopienie blachy stalowej, oraz rozkłady powierzchniowe stężeń podstawowych pierwiastków

Fig. 7. The microstructure of substrate - braze interfacial boundary from the region of local melting of steel sheet and the surface distribution of concentration of the base elements

lutowina-podłoże i brak porowatości spoiny. Cynk tworzy roztwór z miedzią, natomiast krzem segreguje na granicy z żelazem. W miejscach, gdzie doszło do niewielkiego, lokalnego nadtopienia podłoża, tworzy się roztwór Fe-Si. 


\section{Literatura}

[1] Gawrysiuk W.: Technologia lutospawania łukowego. Zalecenia technologiczne i przemysłowe przykłady zastosowania, Przegląd Spawalnictwa 3/2005, s.35-40.

[2] Gawrysiuk W., Pfeifer T., Winiowski A.: Charakterystyka technologii lutospawania łukowego MIG/MAG, Przegląd Spawalnictwa 2-3/2005, s.7-20.

[3] Górka J., Kupiec K.: Technologia lutospawania TIG stalowych ocynkowanych blach karoseryjnych, Biuletyn Instytutu Spawalnictwa 4/2009, s.62-66.

[4] Klimpel A., Górka J., Janicki D., Zyska T., Pniewska A.: Technologia lutospawania laserowego stali austenitycznej, Przegląd Spawalnictwa 9/2007, s.63-70.

[5] Banasik M., Stano S., Dworak J.: Lutospawanie laserowe na stanowiskach zrobotyzowanych, Biuletyn Instytutu Spawalnictwa 5/2012, s.134-139.

[6] De Dompablo M.: Nowe rozwiązania w technologii spawania ColdArc i ForceArc, Przegląd Spawalnictwa 7-8/2009, s.1217.
[7] Klimpel A., Czypryński A., Górka J.: Lutospawanie metodą GMA cienkich blach ocynkowanych, Przegląd Spawalnictwa 8-9/2004, s.81-85.

[8] Różański M., Gawrysiuk W.: Lutospawanie MIG/MAG blach ocynkowanych i przykłady trudno spawalnych układów materiałowych, Przeglą Spawalnictwa 9/2007, s.7-12.

[9] Klimpel A., Czypryński A., Górka J.: Lutospawanie plazmowe PTA złączy doczołowych stalowych blach karoseryjnych dwustronnie galwanizowanych cynkiem, Przegląd Spawalnictwa 9-10/2006, s.72-75.

[10] Klimpel A., Czypryński A., Górka J.: Lutospawanie laserowe ocynkowanych blach karoseryjnych, Biuletyn Instytutu Spawalnictwa 6/2006, s.39-43.

[11] Matusiak J., Pfeifer T.: Niskoenergetyczne metody spawania łukowego w osłonie gazów - wpływ warunków materiałowo-technologicznych na jakość złączy i emisję zanieczyszczeń do środowiska pracy, Biuletynu Instytutu Spawalnictwa 5/2008, s.85-92.

\section{ARTYKUKY ARCHIWALNE PRZEGLĄDU SPAWALNICTWA}

\section{Cena}

Cena 1 artykułu z numeru archiwalnego w wersji elektronicznej: 21 zł (w tym 5\% VAT)

$\mathbf{W}$ celu zamówienia artykułu należy wypełnić formularz zamieszczony obok i przesłać go w formie skanu wraz $z$ potwierdzeniem wpłaty adres:

$$
\text { pspaw@ps.pl }
$$

\section{Wpłaty należy dokonać na rachunek bankowy:} Bank BPH S.A. Oddział w Warszawie 45106000760000320000431836

Artykuły wysyłane są drogą elektroniczną w ciągu 2 dni od otrzymania zamówienia.

\section{REDAKCJA - Przegląd Spawalnictwa AW SIMP}

ul. Świętokrzyska 14a, 00-050 Warszawa tel.: 2282725 42, faks: 223361479

\section{Zamawiam artykuły:}

Nr zeszytu: ..........., rok ............., strony

Nr zeszytu: ..........., rok ............., strony

Nr zeszytu: ..........., rok ............., strony

Adres e-mail

Imię i nazwisko

Firma

Adres

NIP

Kontakt do osoby zamawiającej:

Oświadczam, że jestem podatnikiem VAT i upoważniam firmę do wystawienia faktury bez podpisu 